\title{
Regulatory principles to enhance coherence and to facilitate trade in wine
}

\author{
Greg Hodson and Sara Azevedo \\ Secretary, FIVS, 18 rue d'Aguesseau, 75008 Paris, France
}

\begin{abstract}
The globalization of the wine market has generally outpaced regulatory development. As a result, wine has been introduced to markets with little historical product experience and has been subjected to standard food regulatory approaches that are not always appropriate given its unique characteristics. In addition, disparate regulatory limits and approaches to testing wine in different markets may result in inadvertent obstacles to trade and increased costs of doing business, but provide no counterbalancing benefits to consumers, producers or regulators. This paper presents a series of principles (already endorsed by FIVS) that, if recognized and implemented widely by governments, would have enormous consequences for the facilitation of global trade in wine. Many of these are already being applied among established trading partners, though they are generally not stated explicitly.
\end{abstract}

\section{Summary}

This paper presents several principles surrounding the establishment of regulatory limits for wine and verifying compliance with those limits by analytical methods. In particular, the following principles are presented:

- Avoid establishing limits that stimulate costly and unnecessary analyses.

- Harmonize limits where there is no scientific justification for national or regional differences.

- Give due regard to intergovernmental agreements and work done by other authorities when establishing new regulatory limits.

- Adopt a common system of scientific units for expressing regulatory limits.

- Express regulatory limits on a "per unit volume of wine" basis rather than "per unit volume of alcohol" in the wine.

- Adopt a common way of expressing results where this is done in relation to a single wine constituent (e.g. for Total Acidity expressed in terms of one specific acid).

- Consider the establishment of analytical "action levels" for substances or classes of substances in wine - values below which they will be deemed to all intents and purposes not to be present in the wine.

- Allow suitable transition arrangements when regulatory limits are changed, provided public health considerations so permit.

- Analyses of wine for compliance purposes should be undertaken by suitably accredited laboratories (or overseen by certified analysts) that perform acceptably for the specific test methods used.

- Analytical methods used for wine compliance purposes should be validated and/or have a demonstrably appropriate level of performance for wine.
- For wine authenticity analyses, the database of authentic samples with which the test samples will be compared must be sufficiently comprehensive to avoid the mis-categorization of legitimate samples as fraudulent.

- Laboratories testing for compliance purposes should supply measurement uncertainty information with their analytical results, and the competent authorities should take this into account in interpreting analytical data.

FIVS endorsed these principles in 2013, and it is proposed that they could form the basis for an international, intergovernmental understanding that would have significant trade-facilitating effects.

\section{Introduction}

The facilitation of trade in wine and avoidance of obstacles to trade, according to the rights and obligations of international accords, have always been central tenets by which the work of key international bodies dealing with wine has been conducted.

The purpose of this paper is to propose activity for such international bodies to facilitate trade in wine and to help prevent the creation of unnecessary obstacles to that trade. The suggested action is in the area of the establishment of regulatory limits for wine, and the application of laboratory testing to verify compliance with those limits.

It is clear that regulatory limits are necessary in certain cases to maintain product safety and composition standards, while creating and maintaining a level playing field on which wines may compete in the global market. Limits and methods are good in their proper place and achieve useful purposes in international trade. However, many national regulatory limits were established in days before the wine market became the global entity that it is today. Therefore, there are steps that can and should be 
taken to facilitate wine trade in the $21^{\text {st }}$ century that will have no deleterious impact whatsoever on the protections afforded to consumers and honest traders.

This paper outlines several principles that have been endorsed by FIVS. If implemented by the appropriate governments around the world, these would have a significant positive impact on trade. They would work to reduce confusion and unnecessary costs, as well as to enhance the confidence that all sectors could enjoy in the robustness of laboratory testing results.

For each principle, explanatory background information is supplied. The principles are presented first for the establishment of regulatory limits and then for the laboratory testing that is done to determine compliance with those limits.

\section{Establishment of regulatory limits}

\subsection{Establish only necessary regulatory limits}

Principle: Governments should avoid setting limits that stimulate costly and unnecessary analyses.

The establishment of limits for constituents and potential contaminants in wine is certainly necessary in many cases to provide governments with a degree of comfort surrounding the quality and safety of wines in international trade. However, it is also true that once a regulatory limit has been established, it is often included either in certificates of analysis required by importing countries, or in the private standard documentation that may be necessary to sell product in a given market.

Every analytical test performed on a wine has cost implications for the producer and the multiplication of unnecessary tests can serve to increase the cost of doing business in a given market, eroding margins to a point where it is no longer feasible to trade. Examples of limits that might be considered unnecessary include:

- Establishment of pesticide Maximum Residue Limits (MRLs) for wine when they are already established and effective residue control is exercised at the level of the raw material, grapes.

- Setting specifications for pathogenic microorganisms for wine, which does not support the growth of such organisms because of its content of acid and alcohol. We know that the results of an analysis for salmonella in wine will always show that it is not present. To perform a test to demonstrate what is already known is costly and wasteful.

- Setting a limit at a level much higher than quantities ever seen in wines around the world. The establishment of the limit means that costly confirmatory analyses will be performed, but no products will actually fail to comply.

\subsection{Harmonize regulatory limits where possible}

Principle: Governments should harmonize limits where there is no scientific justification for national or regional differences.

The limits established for many components in wine relate to elements of composition and have no public health significance. In a global market, trading in wine
Table 1. International methanol limits for wine.

\begin{tabular}{|l|l|}
\hline \multicolumn{2}{|l|}{ Limits expressed on a volume methanol/volume wine basis } \\
\hline Argentina & $0.35 \mathrm{~mL} / \mathrm{L}$ of wine (about $280 \mathrm{mg} / \mathrm{L})$ \\
\hline Limits expressed on a weight methanol /volume wine basis \\
\hline OIV & $\begin{array}{l}400 \mathrm{mg} / \mathrm{L} \text { of wine (Red) } \\
250 \mathrm{mg} / \mathrm{L} \text { of wine (White and Rosé) }\end{array}$ \\
\hline Canada (Ontario) & $400 \mathrm{mg} / \mathrm{L}$ of wine \\
\hline Canada (Quebec) & $0.4 \mathrm{~g} / \mathrm{L}$ of wine (400 mg/L) \\
\hline China & $\begin{array}{l}300 \mathrm{mg} / \mathrm{L} \text { of wine }(\text { Red) } \\
250 \mathrm{mg} / \mathrm{L} \text { of wine (white \& rosé) }\end{array}$ \\
\hline Japan & $1 \mathrm{mg} / \mathrm{cm}^{3}$ of wine $(1000 \mathrm{mg} / \mathrm{L})$ \\
\hline South Africa & $300 \mathrm{mg} / \mathrm{L}$ of wine \\
\hline Switzerland & $\begin{array}{l}300 \mathrm{mg} / \mathrm{L} \text { of wine (red \& white) } \\
150 \mathrm{mg} / \mathrm{L} \text { of wine (rosé) }\end{array}$ \\
\hline Limits expressed on a weight methanol $/$ weight wine basis \\
\hline Turkey & $10 \mathrm{mg} / \mathrm{kg}$ of wine (about $10 \mathrm{mg} / \mathrm{L})$ \\
\hline Limits expressed on a weight methanol/ volume of \\
alcohol in wine basis
\end{tabular}

can become very difficult when each market has different limits for the same component. Frequently, there is no scientific justification for the differences in limits observed between markets. As an example, see Table 1, which, by way of illustration only, presents limits established around the world for methanol content in wine. These levels are comparable to what one would expect to find in freshly squeezed fruit juices, and the limits are set for technological rather than toxicological reasons (as a means to ensure that sound fruit was used in the production of wine). It is instructive to see how many numerically different limits there are for just this one component of wine. This scenario can be repeated for many other substances for which limits are imposed on wine in international trade.

Wine trade would be greatly facilitated if such limits, where they are necessary, could be set at the same level in the different markets around the world.

\subsection{Take due account of intergovernmental agreements and work done by other governments when establishing a new regulatory limit}

Principle: Governments should give due regard to intergovernmental agreements and work done by other authorities when establishing new regulatory limits.

Where authorities decide that a new regulatory limit needs to be established for wine, this should 
be done with reference to limits already introduced by other authorities or recommended by appropriate intergovernmental organizations. If those limits exist, are suitably justified by the available science and are applicable taking account of any national or regional considerations in the country proposing to introduce the new limit, it would foster harmonization if the limit established was consistent with that imposed or recommended elsewhere.

\subsection{Use common scientific units for the expression of regulatory limits}

Principle: Governments should adopt a common system of scientific units for expressing regulatory limits.

It is frequently the case when limits are set by governments, that they are expressed using different scientific units than those used in other markets. This causes enormous confusion in international wine trade. Table 1 shows that there are no less than 5 different ways which governments have chosen to express limits for methanol in wine. Note, also, that even where authorities set a limit that is identical quantitatively, they sometimes choose to express it differently in terms of units. For example, Ontario and Quebec apparently have the same limit for methanol but express it in different units. Methanol is only an illustrative example here of the confusion that exists for all other regulatory limits established for wine around the world.

The US wine industry considered this problem from a purely domestic standpoint (where use of different units to express the same quantities can be problematic). They recommended to the US producers the adoption of a common set of units for expressing wine related values [1].

It would be greatly beneficial to trade in wine around the world if governments could reach agreement about the system of scientific units to be used in the expression of regulatory limits.

\subsection{Use a common basis for the expression of regulatory limits}

3.5.1. Regulatory limits for wine expressed on a per unit of alcohol basis

Principle: Governments should express regulatory limits on a "per unit volume of wine" basis rather than "per unit volume of alcohol" in the wine.

The information in Table 1 reveals that some governments establish limits for methanol on the basis of the volume of alcohol in the wine and not on the volume of the wine itself. This means that as the alcohol (ethanol) content of a wine decreases, the relative content of a given substance expressed per unit volume of alcohol will increase (illustrated in Table 2).

This form of expressing regulatory limits is occasionally seen in regulatory proposals from various parts of the world, and has several negative consequences:

- It introduces the confusion of expressing a limit in a different way than other countries do (see 3.3 above).

- It can result in wines with lower alcohol contents approaching or exceeding regulatory limits, and
Table 2. Methanol expressed per unit volume of alcohol.

\begin{tabular}{|l|c|c|}
\hline $\begin{array}{c}\text { Alcohol by } \\
\text { Volume in } \\
\text { wine }(\%)\end{array}$ & $\begin{array}{c}\text { Methanol (mg) } \\
\text { in 1 litre wine }\end{array}$ & $\begin{array}{l}\text { Methanol (mg) } \\
\text { per litre of alcohol } \\
\text { in the same wine }\end{array}$ \\
\hline 15 & 100 & 670 \\
\hline 14 & 100 & 710 \\
\hline 13 & 100 & 770 \\
\hline 12 & 100 & 830 \\
\hline 11 & 100 & 910 \\
\hline
\end{tabular}

therefore may effectively discourage producers from reducing the alcohol in their products to meet consumer demand.

- Occasionally, governments have proposed regulatory limits on a per unit volume of alcohol basis, but have used numerical values more appropriate for a limit expressed on the total volume of wine. In these cases, the proposed limits would effectively have prevented any wine from entering the country because none could be made to be in compliance with them.

Note that the consumer is not exposed to any more or less of the limited substance by drinking a glass of any of the wines shown in Table 2 above, because the content of methanol (in this case) per unit volume of the wine is the same in each case.

Thus, it may be seen that limits set on the basis of the volume of alcohol in the wine seem not to be in the best interests of consumers or producers.

\subsubsection{Different acids used as the basis for titratable acidity results expression}

Principle: Governments should agree on a common way of expressing results where this is done in relation to a single wine constituent.

Many wine producing countries choose to establish limits for the amount of titratable acidity (TA) that a wine may contain. However, some choose to calculate the acidity measurement as though all the acid measured had been tartaric acid, and to express the limit in that way. Other countries choose to calculate as though all the acid had been sulphuric acid and express the limit in that way. Although two limits may be identical, basing the expression of the limit in terms of different acids makes them look different and introduces the possibility for confusion in trade.

If there are other limits that are expressed in terms of a single wine constituent, but where different countries have chosen different substances for this purpose, this should also be reviewed on the basis of this principle.

\subsection{Establish analytical "action level" provisions}

Principle: Where appropriate, and where consistent with public health considerations, governments should consider the establishment of analytical "action levels" for substances or classes of substances in wine - levels below which they will be deemed to all intents and purposes not to be present in the wine. 
Over the last 10-20 years, great strides have been made in the performance of analytical methods. It has become possible to measure smaller and smaller quantities of substances in wine, whether grape components or other chemicals that find their way into the product in the course of normal winegrowing operations.

When regulations are framed in such a way that the presence (at any level) of a substance is illegal, or else triggers some labelling requirement, they clearly have the potential to cause problems when combined with increasing analytical method sensitivity. Taken to the logical extreme, one molecule of a substance in a bottle of wine (if it could be measured) would be "presence" and could determine the legality of the product and/or that of its label.

The scope for detecting the presence of adventitious substances in wine grows larger and larger with the analytical ability to detect smaller and smaller amounts. Such low levels could often not have been detected with methods of analysis and analytical technology from even 5 years ago, and are so low as to pose no known health risks. Yet they can, and do, increasingly result in market access problems for wines subjected to more advanced analytical methodologies.

In this situation, it would be helpful to establish "action levels" for certain compounds or classes of compounds - below which the substance(s) would not be counted as "present" for enforcement purposes. These would be established at a level to fully preserve consumer protections but to mitigate the potentially increasing trade issues that may arise in the next few years as analytical methods continue to grow in sensitivity. By way of an existing example of this principle, some authorities already operate a default (very low) Maximum Residue Limit for agrochemicals where no specific numerical limit has been established.

\subsection{Transition arrangements}

Principle: Governments should agree upon and allow suitable transition arrangements when limits are changed, provided public health considerations so permit.

From time to time, governments revise the limits in their regulations for various reasons. Wherever possible, this should be an effort harmonized with other countries (see 2.2 above). There have been cases where limits have been lowered and enforcement action has begun immediately, even for issues where there was no pressing public health concern. Action has been commenced against wine that was produced perhaps 18 months to 2 years before the regulatory change was made and that was in complete compliance with the rules then in existence. Product has even been shipped from the producing country in perfect compliance with the rules then in force, only to arrive at the destination market as a non-compliant product because new rules were implemented with immediate effect.

Wine is a product with a potentially long shelf life. Thus, it is also important when regulatory provisions are revised that consideration be given to grandfathering stocks of product that are already produced and in market but have significant shelf life remaining, so that they are not inadvertently and unnecessarily disadvantaged by changes in regulatory provisions. Naturally, this would only operate where there were no overriding public health concerns.

In this situation, it would be very helpful for an agreement to be reached around transition timetables and grandfathering arrangements for various kinds of proposed regulatory changes (e.g. for labelling, composition, etc.) in cases where there is no pressing need to act for public health reasons.

\section{Laboratory testing}

\subsection{Accredited laboratories and Certified analysts}

Principle: Analyses of wine for regulatory purposes should be undertaken by suitably accredited laboratories (or overseen by suitably certified analysts) which perform acceptably for the specific test methods used.

Laboratory accreditation systems and certification of laboratory analysts are means to ensure that Good Laboratory Practice is being followed within an analytical laboratory for certain analyses that it performs. This gives a level of confidence in the results that a laboratory produces.

Proficiency testing programs provide a means to determine how a laboratory performs for a given analysis in comparison with other laboratories, and can highlight systematic problems and lead to corrective actions.

The authorities in some jurisdictions offer certification programs for commercial and/or producer laboratories (or analysts), indicating that those labs or individuals have demonstrated proficiency with analyses required in international trade. The results produced by such laboratories with those methods can then be used on certificates of analysis or in other international trade scenarios, and the certified analyst can officially sign the documentation.

As far as possible, it would be helpful if those laboratories that perform analyses related to the international trade in wine were accredited or had certified analysts for the methods they use for international trade purposes and could demonstrate an adequate level of performance for each of those methods.

\subsection{Validated methods}

Principle: Analytical methods used for wine regulatory purposes should be validated and/or have a demonstrably appropriate level of performance for wine.

Many laboratories that test wines for compliance with appropriate regulatory standards do so with methods which are validated in some way. Often this will mean that the method has been tested by 8-12 laboratories for the same sample(s) of the product for which the method is intended to be used and has demonstrated adequate performance for accuracy, repeatability etc.

It is clearly important for the international wine trade that the methods used to analyse the wines for compliance purposes are validated or have been shown by robust means to have performance characteristics that are acceptable when applied to wine. 


\subsection{Authenticity methods}

Principle: For wine authenticity analyses, the database of authentic samples with which the test samples will be compared must be sufficiently comprehensive to avoid the mis-categorization of legitimate samples as fraudulent.

In almost all methods for determining wine authenticity, samples are tested for a certain characteristic and the results are then compared with those from known authentic wines. When a method is applied to wines whose origin or method of cultivation/production is not represented in the database of authentic samples with which its results are compared, there is a real risk of miscategorising authentic wines as fraudulent.

It should therefore be a recognized principle in the authenticity testing of wine, that all the factors that might potentially influence the result of an analytical procedure are identified and taken into account in the construction of the database of authentic wines. Such factors may include (inter alia) production region, soil, rootstock, clone, variety, irrigation, trellising and pruning systems, leaf thinning, crop thinning, climate, microclimate, season and all the possible permutations of winemaking practices that could legitimately have been used in the production of the wine, together with the age of the sample and the conditions under which it has been stored.

\subsection{Measurement uncertainty}

Principle: Laboratories testing for compliance purposes should supply measurement uncertainty information with their analytical results and the competent authorities should take this into account in interpreting analytical data.

In 2011, the Methods of Analysis and Sampling Committee of the Codex Alimentarius Commission (CCMAS) elaborated a revised explanatory note to an existing set of guidelines concerning measurement uncertainty [2]. The note makes it clear that it is anticipated that laboratories should assess the analytical uncertainty surrounding the determinations they make, and that they should make this information available on request. In international trade situations, the note anticipates that the request for this information would be made. It would clearly be a step towards objective and consistent enforcement for wines in international trade if the measurement uncertainty surrounding the various analyses was provided by the laboratories conducting the analysis, and if that information was taken into account in any decision to pursue enforcement action.

\section{Conclusion}

This document has proposed and explained several principles surrounding the establishment of regulatory limits and the laboratory testing that is performed in connection with the regulations of international trade in wine. If all the principles mentioned above were uniformly adopted and applied by countries that trade in wine, the implications for market access and free movement of goods would be significant, but there would be no decrease in the level of protection that was afforded to consumers. Accordingly, a study of these principles by relevant governments is warmly commended, to see whether they might form the basis for an understanding among countries on these matters.

\section{References}

[1] G. Burns, A. Caputi jr., Am. J. Enol. Vitic. 53, 222223 (2002)

[2] Codex Alimentarius Commission, Guidelines on Measurement Uncertainty - Roma:FAO/WHO Joint Publications; Report No.: CAC/GL 54, 2004 (2011) 